\title{
Apical Membrane Limits Urea Permeation Across the Rat Inner Medullary Collecting Duct
}

Robert A. Star*

*Department of Internal Medicine, University of Texas Southwestern Medical Center, Dallas, Texas 75235

\begin{abstract}
Urea diffuses across the terminal inner medullary collecting duct (IMCD) via a facilitated transport pathway. To examine the mechanism of transcellular urea transport, membrane-apparent urea $\left(P_{\text {urea }}\right)$ and osmotic water $\left(P_{f}\right)$ permeabilities of IMCD cells were measured by quantitative light microscopy in isolated IMCD-2 tubules perfused in the absence of vasopressin. Basolateral membrane $P_{\mathrm{f}}$, determined by addition of raffinose to the bath, was $69 \mu \mathrm{m} / \mathrm{s}$. Basolateral membrane $P_{\text {urea }}$, determined by substituting urea for raffinose without change in osmolality, was $14 \times 10^{-5} \mathrm{~cm} / \mathrm{s}$. Bath phloretin inhibited basolateral $\boldsymbol{P}_{\text {urea }}$ by $85 \%$ without a significant effect on $\boldsymbol{P}_{\mathrm{f}}$. The basolateral reflection coefficient for urea, determined by addition of urea in the presence of phloretin, was 1.0. These results indicate that urea crosses the basolateral membrane by diffusion, and not by solvent drag. In perfused tubules, the rate of cell swelling following substitution of urea for mannitol was significantly greater with bath than lumen changes. After correcting for membrane surface area, the basolateral membrane was twofold more permeable than the apical membrane. Conclusions: $(a)$ in the absence of vasopressin, urea permeation across the IMCD cell is limited by the apical membrane; (b) the basolateral membrane contains a phloretin-sensitive urea transporter; $(c)$ transepithelial urea transport occurs by movement of urea through the IMCD cell. (J. Clin. Invest. 1990. 86:1172-1178.) Key words: urea transporter • reflection coefficient $\bullet$ phloretin $\bullet$ concentrating mechanism
\end{abstract}

\section{Introduction}

Accumulation of urea in the inner medulla, required for the kidney to generate a maximally concentrated urine (1), occurs by efflux of urea across the inner medullary collecting duct $(\operatorname{IMCD})^{1}(2,3)$. There is axial heterogeneity of urea transport across the IMCD, the initial one-third (initial IMCD) has a low urea permeability, while the distal two-thirds (terminal IMCD) has a high basal urea permeability which is further increased

Address correspondence and reprint requests to Dr. Robert A. Star, Department of Internal Medicine, Division of Nephrology, University of Texas Southwestern Medical Center, 5323 Harry Hines Boulevard, Dallas, TX 75235-8856.

Received for publication 12 March 1990 and in revised form 31 May 1990.

1. Abbreviations used in this paper: DIC, differential interference contrast; IMCD, inner medullary collecting duct; NUS, non-urea solute; $P_{\mathrm{f}}$, osmotic water permeability; $\mathrm{P}_{\text {urea }}$, urea permeability; $\sigma$, reflection coefficient.

J. Clin. Invest.

(c) The American Society for Clinical Investigation, Inc.

$0021-9738 / 90 / 10 / 1172 / 07 \$ 2.00$

Volume 86, October 1990, 1172-1178 by vasopressin $(2,4)$. This functional heterogeneity, which serves to maximize urea accumulation in the deepest portions of the inner medulla (4), is paralleled by marked morphologic heterogeneity $(5,6)$. The initial IMCD contains cells similar to those found elsewhere in the collecting duct (principal and intercalated cells), while the terminal IMCD is composed of a new cell type called the IMCD cell $(5,6)$. Compared with the principal cell, the IMCD cell has a pale cytoplasm, lacks a central apical cilium which is characteristic of a principal cell (6), and can be identified by differential interference contrast microscopy (7). The distribution of IMCD cells coincides with the distribution of vasopressin-stimulated urea transport $(2,6)$, suggesting that the IMCD cell effects urea transport across this terminal portion of the collecting duct.

Previous studies employing measurements of transepithelial urea transport have suggested that urea diffuses across the IMCD via a specialized transport pathway. The IMCD epithelium is much more permeable to urea than to other non-electrolytes (creatinine and raffinose) whose transport is restricted to the paracellular pathway, suggesting that most of urea diffusion across the epithelia is transcellular (4). The transepithelial urea permeability is $\sim 100$-fold greater than that predicted on the basis of lipid-phase permeation $(2,4)$, leading to the suggestion that transepithelial urea transport occurs by a facilitated pathway present on both apical and basolateral membranes (8). Transepithelial urea transport is inhibited by phloretin (8-10), is competitively inhibited by urea analogues (8), displays saturation kinetics (8), and is separate from the water pathway $(11,12)$. The erythrocyte urea pore has similar characteristics (13-15), suggesting that the erythrocyte and IMCD transporter are similar.

The IMCD cell also transports water $(16,17)$. Water transport in the collecting duct and toad urinary bladder is limited by the apical membrane whose water permeability is regulated by vasopressin $(18,19)$. However, similar information for urea transport is unavailable because previous studies have only measured transepithelial urea permeability, which can not discern the transport properties of the individual apical and basolateral membranes. Therefore, we devised a method for measuring the urea permeability of individual membranes in a polarized epithelium, allowing the determination of the barrier to diffusion of urea across the cells. Measurement of membrane urea permeability is complicated by the possibility of solvent drag, i.e., convective transport of urea through water channels. Therefore, we measured the urea reflection coefficient $\left(\sigma_{\text {urea }}\right)$.

\section{Methods}

Tubule preparation. IMCD from kidneys of $60-120-\mathrm{g}$ pathogen-free Harlan Sprague-Dawley rats (Harlin, Indianapolis, IN) were isolated and perfused in vitro using previously described techniques (20). Rats were given furosemide $(6 \mathrm{mg} / 100 \mathrm{~g}$ body wt i.p.; Elkins-Sinn, Inc., Cherry Hill, NH) for 20-30 min before the kidneys were harvested (2, 20). Tubules were dissected at $17^{\circ} \mathrm{C}$ in a solution (solution $\mathrm{A}$ ) contain- 
ing (in mM): $\mathrm{NaCl} 120, \mathrm{NaHCO}_{3} 25, \mathrm{~K}_{2} \mathrm{HPO}_{4} 2, \mathrm{CaCl}_{2} 2$, glucose 5, and $\mathrm{MgSO}_{4} 1.2$; osmolality $280 \mathrm{mosmol} / \mathrm{kg} \mathrm{H}_{2} \mathrm{O}$. In some experiments, $100 \mathrm{mosmol} / \mathrm{kg} \mathrm{H}_{2} \mathrm{O}$ raffinose (Sigma Chemical Co., St. Louis, MO), mannitol (Sigma Chemical Co.), or urea (Sigma Chemical Co.) was added to the above solution. Tubule segments were dissected from the middle third of the inner medulla; the distal end of the tubule was always at the junction between IMCD-2 and IMCD-3. Dissected tubules were mounted on concentric pipettes for in vitro microperfusion at $37^{\circ} \mathrm{C}$ using methods of Burg (21). Perfused tubules were mounted in a laminar flow bath chamber with a volume of $\sim 70 \mu \mathrm{l}$ which facilitated rapid exchanges of bathing solution (22). Perfusate and bathing systems were designed to allow rapid changes between several fluids with minimal movement of the tubule $(7,18,22)$. The perfusate solutions could be exchanged with a $t_{1 / 2}$ of $204 \pm 2 \mathrm{~ms}(n=2)$ (Fig. 1; left); the bath solutions could be exchanged with a $t_{1 / 2}$ of $76 \pm 14 \mathrm{~ms}(n=3)$ (Fig. 1; right). The temperature and $\mathrm{pH}$ were carefully controlled at $37.5^{\circ} \mathrm{C}$ and 7.4 , respectively. Osmolality was measured by freezing point depression (model 3W2; Advanced Instruments, Inc., Needham Heights, MA) or vapor pressure (model 5500; Wescor, Inc., Logan, UT) osmometry.

Microscopy. Tubules were observed by video-enhanced differential interference contrast (DIC) optics (22) illuminated with green light (P10-550; Corion Corp., Holliston, MA) using a 63× oil immersion objective (Neofluor, 1.25 N.A.; E. Leitz, Inc., Rockleigh, NJ) and a $32 \times$ objective condenser lens ( 0.40 N.A.; Carl Zeiss, Inc., New York). DIC images of the lateral tubule wall were continuously recorded by a television camera (model 65; Dage-MTI, Inc., Michigan City, IN) coupled to a super-VHS video tape recorder (model HR-8000U; JVC, Elmwood Park, NJ). Timing information was provided by a video timer (model VTG-33; FOR-A Corp., Newton, MA). Images were enhanced either electronically (model IV-530 Contour Synthesizer; FOR-A Corp.) or digitally (series 150; Imaging Technologies, Woburn, MA), and saved by a video copy processor (P70U; Mitsubishi, Cypress, CA). The final image was viewed on a TV monitor (PVM-1271Q; Sony, Park Ridge, NJ) at a final magnification of 3,500.

Cells were imaged on the lateral tubule wall. The focal plane was chosen so the apical and basolateral membranes were as sharp as possible, which generally was through the center of the nucleus. Great care was taken to insure that the cell studied did not contribute to the curvature of the tubule. Only a single cell could be successfully imaged in any given lateral wall image so that the number of cells equaled the number of tubules.

Measurement of changes in cell height as a marker for changes in cell volume. In preliminary studies, we found that IMCD cells changed volume very rapidly after changes in bath composition (addition of raffinose or replacement of raffinose with urea), reaching a new steady state cell volume within 2 to $4 \mathrm{~s}$. Such rapid changes in cell volume preclude measuring actual cell volume (18). However, changes in cross-sectional area, which can be recorded 30 times per second, have been correlated with changes in cell volume (18). This approximation
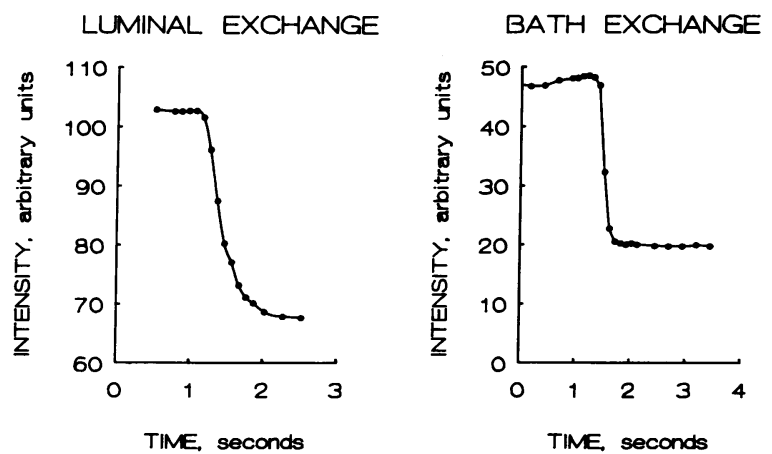

Figure 1. Rate of luminal and bath fluid exchange. Green dye was added to luminal (left) or basolateral solution (right). Optical transmission was measured at $550 \mathrm{~nm}$. works because cells swell and shrink primarily in the radial direction (i.e., by changing cell height) $(18,23)$. While we could obtain excellent images of rat cortical collecting ducts and hamster IMCD-2 tubules, the lateral cell membranes and intercellular spaces of rat IMCD cells on the lateral tubule wall were usually indistinct for unknown reasons. Therefore, we used changes in cell height as a measure of relative change in cell volume. We assumed that the cell behaves as a right noncircular cylinder whose volume is determined only by changes in cell height. The maximum error caused by assuming a cylindrical rather than an annular cell geometry in relative cell volume is less than 4-5\% (calculated for tubule OD of $40 \mu \mathrm{m}$, and cell height changing from 7 to $5.25 \mu \mathrm{m}$ ). This geometric assumption is valid since the longitudinal cell length does not change (23), and because the interspace volume is small relative to cell volume (23). Furthermore, we did not see extensive changes in the interspace volume (in cells at the top or bottom of the tubule) during any of the protocols (unpublished observations). The cell volume was calculated by multiplying the cell height times the area of a perpendicular section. The latter value was determined from en face images of in vitro perfused IMCD cells either on the upper or lower wall of the tubule. In 15 cells studied, the average area of a perpendicular section was $105 \pm 5 \mu \mathrm{m}^{2}$.

For each cell studied, cell height (actually mean cell height) was measured over a fixed span of the lateral tubule wall that approximated that of a single IMCD cell. The apical and basolateral membranes of a cell were traced by a semiautomatic process using a cross correlation technique (24). The cell height was calculated by dividing the traced cross-sectional area by the longitudinal extent of the traced area. The average cell height measured of in vitro IMCD cells perfused with symmetric solutions at $285 \mathrm{mosmol}$ was $6.6 \pm 0.3 \mu \mathrm{m}(n=10)$, which agrees well with that of fixed IMCD cells $(7.1 \mu \mathrm{m})(6)$.

Apical and basolateral membrane surface area. The apical membrane area for an individual IMCD cell was obtained by multiplying the measured perpendicular cross sectional area (see above) times the apical membrane amplification factor. The apical membrane application factor of 3.8 was calculated by dividing the reported apical surface areas per unit length tubule (6) by the smooth apical surface area per unit length tubule ([6] and personal communication with Dr. Clapp, University of Alabama at Birmingham). Therefore, the apical membrane area for an individual IMCD cell used in subsequent permeability calculations was $398 \mu \mathrm{m}^{2}\left(3.8 \times 105 \mu \mathrm{m}^{2}\right)$. The basolateral membrane surface area of an IMCD cell and the reported ratio of the basolateral to apical membrane surface area per unit length of tubule (6) was calculated from this latter number, yielding $1615 \mu \mathrm{m}^{2}$.

Measurement of membrane osmotic water permeability. Tubules were dissected, perfused, and bathed in solution A. After a 40-min equilibration period, allowing transepithelial osmotic water permeability $\left(P_{f}\right)$ to return to a basal state (4), transport across the apical membrane was blocked by perfusing the lumen with silicone oil (18) or an inert fluorinated hydrocarbon (Fluorinert FC-75; 3M, St. Paul, MN). Within $5 \mathrm{~min}$, raffinose ( $100 \mathrm{mosmol} / \mathrm{kg} \mathrm{H}_{2} \mathrm{O}$ ) was suddenly added to the bath solution, and cell height was recorded at 10-15 frames/s. Preliminary calculations using a mathematical model of cell volume (see below) indicated that the initial decrease of cell volume would be best approximated by an exponential function rather than a straight line. Therefore, the data were transformed logarithmically, and $t_{1 / 2}$ was determined by linear regression analysis of data from the first $300 \mathrm{~ms}$ of the tracing. Membrane $P_{\mathrm{f}}$ was calculated by parameter estimation from the experimentally determined $t_{1 / 2}$ using a mathematical model. ${ }^{2}$

Measurement of basolateral membrane-apparent urea permeability. Membrane urea permeability $\left(P_{\text {urea }}\right)$ was determined following

2. To estimate $P_{\mathrm{f}}$ in each tubule, simulations were run using the cell volume model (see Appendix). The initial cell and bath concentrations of NUS, cell volume, and membrane surface area were set equal to the measured values for each tubule studied. The NUS permeability was set to zero, and $\sigma_{\mathrm{NUS}}$ was set to $1 . P_{\mathrm{f}}$ was estimated using a one-dimensional Newton's method which minimized the difference between the measured and simulated $t_{1 / 2}$ over the first $300 \mathrm{~ms}$. 
substitution of 100 mosmol/ $/ \mathrm{kg} \mathrm{H}_{2} \mathrm{O}$ urea for 100 mosmol $/ \mathrm{kg} \mathrm{H}_{2} \mathrm{O}$ raffinose in the bath solution. Because bath osmolality remained constant, we will refer to this maneuver as 'isosmotic addition of urea'. The rationale for this protocol is that urea rapidly enters the cell, raising the cell osmolality, which secondarily leads to an influx of water, causing cell swelling. Preliminary mathematical modeling and initial observations indicated that isosmotic addition of urea increased cell volume in a linear fashion. Therefore, the initial slope of the first $300-500 \mathrm{~ms}$ of the tracing was determined by linear regression analysis. The membrane $P_{\text {urea }}$ was calculated from the experimentally determined slope by parameter estimation assuming that urea crosses the basolateral membrane only by diffusion (i.e., $\sigma_{\text {urea }}=1$ ). This estimate was made as described, ${ }^{2}$ except that $P_{\text {urea }}$ was estimated by minimizing the difference between the simulated and experimental linear slope over $300-500 \mathrm{~ms}$. The cell membrane $P_{\mathrm{f}}$ was set equal to the measured value for that cell, and $\sigma_{\text {urea }}$ was set to 1 .

Preliminary mathematical modelling of this protocol indicated a nonlinear relationship between $P_{\text {urea }}$ and the initial rate of cell swelling. While the relationship is linear for $P_{\text {urea }}$ less than $2.5-5 \times 10^{-5} \mathrm{~cm} / \mathrm{s}$ (using $P_{\mathrm{f}}=70 \mu \mathrm{m} / \mathrm{s}$ ), at larger $P_{\text {urea }}$ 's, the relationship is nonlinear because the finite basolateral water permeability limits the rate of cell swelling. Because of the strong dependence of $P_{\text {urea }}$ on $P_{\mathrm{f}}$, we measured the basolateral water and urea permeabilities in the same cell.

Measurement of $\sigma_{\text {urea }}$ in the presence of phloretin. The basolateral $\sigma_{\text {urea }}$ was measured in the presence of $0.25 \mathrm{mM}$ phloretin, which inhibits $P_{\text {urea }}$ but not $P_{\mathrm{f}}$ (see Results). Tubules were set up, perfused, and bathed with solution A. After $\mathbf{4 0} \mathrm{min}$, the lumen was perfused with fluorinated hydrocarbon, and $0.25 \mathrm{mM}$ phloretin was added to the bath solution. $5 \mathrm{~min}$ later, basolateral $P_{\mathrm{f}}$ then basolateral $P_{\text {urea }}$ were measured as described above (mannitol substituted for raffinose). The basolateral solution was then switched to solution $A$ for $30-60 \mathrm{~s}$, washing urea out of the cell. In the third period, urea $(100 \mathrm{mosmol} / \mathrm{kg}$ $\mathrm{H}_{2} \mathrm{O}$ ) was added to the bath solution, increasing bath osmolality by 100 mosmol $/ \mathrm{kg} \mathrm{H}_{2} \mathrm{O}$. We reasoned that cell height should decrease transiently (because of osmotic abstraction due to the increased osmolality of the bath) then increase back toward the initial cell height (because of urea entry into the cell). The resultant biphasic change in cell height was used to calculate the basolateral membrane $P_{\text {urea }}$ and $\sigma_{\text {urea. }}{ }^{3}$

Mathematical model of cell volume. Because of the complexity of simultaneous water and urea fluxes, we developed a mathematical model for use in experimental design, parameter estimation, and interpretation of experimental data. The model is described in detail in the Appendix. The model consists of three mass balance equations that are solved for cell volume, cell urea, and the amount of non-urea solutes (NUS) in the cell as a function of time. The fluxes of urea, NUS, and water into the cell across the apical and basolateral membranes are described separately by standard nonequilibrium thermodynamic equations. In all simulations, we assume that the membranes are impermeable to all solutes except urea.

Statistics. All results report as a mean $\pm 1 \mathrm{SE}$. Statistical significance was determined using $t$ tests (paired and unpaired). $P<0.05$ indicated statistical significance.

\section{Results}

Basolateral $P_{f}$ and $P_{\text {urea }}$. Increase in basolateral solution osmolality by addition of raffinose $\left(100 \mathrm{mosmol} / \mathrm{kg} \mathrm{H}_{2} \mathrm{O}\right)$ caused an

3. This estimate was made as described, ${ }^{2}$ except that $P_{\mathrm{f}}$ and $\sigma_{\text {urea }}$ were varied systematically using a two-dimensional parameter search (subroutine DUMINF; IMSL, Houston, TX) to find the values that minimized the sum of squared deviations (simulated minus experimental) of cell volume at all experimental data points. The cell membrane $P_{\mathrm{f}}$ was set equal to the measured value for that cell. Because of concern that the optimal $P_{\mathrm{f}}$ and $\sigma_{\text {urea }}$ would depend on the initial guess, we started the search at several widely different points in several cases. The final results were insensitive to the starting values.

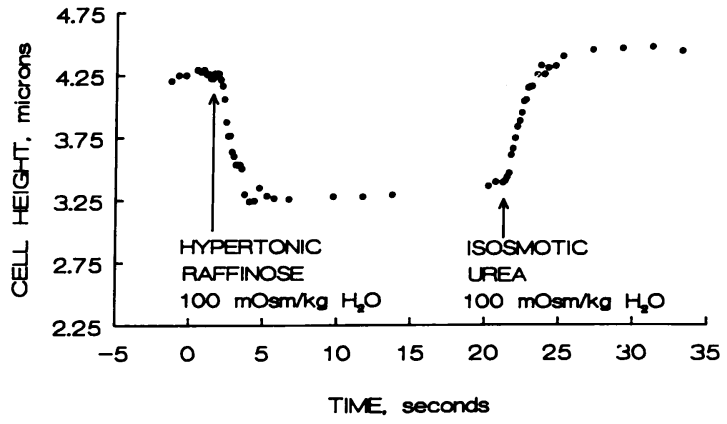

Figure 2. Typical experiment showing changes in cell height of IMCD cell in response to rapid addition of raffinose (bath osmolality 280-380 mosmol/ $\mathrm{kg} \mathrm{H}_{2} \mathrm{O}$ ), and rapid replacement of urea (100 mos$\mathrm{mol} / \mathrm{kg} \mathrm{H}_{2} \mathrm{O}$ ) for raffinose without change in bath osmolality. The vertical arrow indicates the point at which the solution was changed.

exponential decrease in cell height (and hence cell volume; see Methods) until a new steady-state was reached. A typical experiment is shown in Fig. 2. We did not see cell volume regulation in the absence of vasopressin, in agreement with Sun and Hebert (23). In the six tubules studied, the steady-state percent change in cell height was $22.5 \pm 1.3 \%$, which is statistically different from the $25.6 \%$ expected if the cells behaved as a perfect osmometer. This indicates that $86 \%$ (i.e., 22.5/25.6) of the cell volume is osmotically active (see Discussion), in agreement with Flamion and Spring (25). The initial decrease in cell height occurred with a time constant of $509 \pm 57 \mathrm{~ms}$, which corresponds to a surface area-corrected $P_{\mathrm{f}}$ of $69 \pm 13 \mu \mathrm{m} / \mathrm{s}$.

In the second period, the basolateral membrane $P_{\text {urea }}$ of the same cell was measured by sudden replacement of basolateral raffinose by urea $\left(100 \mathrm{mosmol} / \mathrm{kg} \mathrm{H}_{2} \mathrm{O}\right)$ without change in osmolality ('isosmotic addition of urea') (Fig. 2). We reasoned that rapid entry of urea into the cell should raise cell osmolality, causing an influx of water and hence cell swelling. Cell height increased at a rate of $25.0 \pm 4.9$ percent/s to a steadystate height that was $29.6 \pm 3.5 \%$ above that of the control (not significantly different from $35.7 \%$ predicted for a perfect osmometer). The calculated surface area-corrected basolateral membrane $P_{\text {urea }}$ was $14.2 \pm 4.2 \times 10^{-5} \mathrm{~cm} / \mathrm{s}($ or $1.42 \mu \mathrm{m} / \mathrm{s}$ ), assuming $\sigma_{\text {urea }}=1$ (see below).

Effect of phloretin on basolateral membrane water and urea transport. To show that the cell swelling in the preceding protocol was induced by urea transport and not due to some other transport processes, we measured the effect of the lipid soluble urea transport inhibitor phloretin (13). Phloretin had no significant effect on basolateral water permeability in five tubules perfused with oil (Fig. 3). The effect of phloretin on basolateral urea transport was measured in five separate tubules. Tubules were dissected, perfused, and bathed with a solution A containing 100 mosmol/ $\mathrm{kg} \mathrm{H}_{2} \mathrm{O}$ of mannitol. In these experiments, the lumen was not blocked with oil. The rate of cell swelling induced by sudden isosmotic addition of urea (100 mosmol/ $/ \mathrm{k} \mathrm{H}_{2} \mathrm{O}$; urea replacing mannitol) was measured in the absence and presence of $0.25 \mathrm{mM}$ phloretin added to the basolateral bathing solution (Fig. 4). In five tubules, addition of phloretin for $1 \mathrm{~min}$ caused a significant and reversible $55.4 \pm 9.4 \%$ reduction in the initial rate of cell height increase (control: $25.2 \pm 5.3$; phloretin: $9.7 \pm 1.1$; recovery: $23.0 \pm 6.0$ percent/s). Because phloretin is lipid soluble (34), bath phloretin could block transepithelial urea transport at either the lu- 


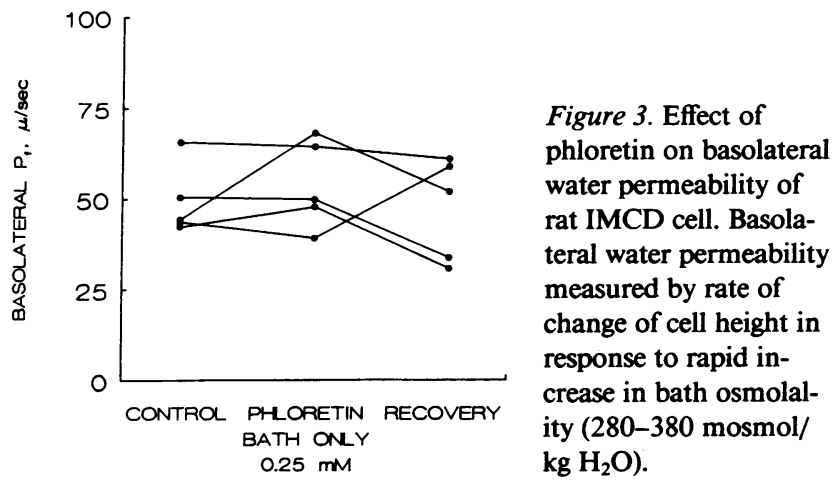

minal or basolateral membranes. The site of action can be determined in this protocol, since urea transport across the apical membrane was not blocked. If phloretin predominantly inhibited urea transport at the apical membrane, the rate of cell swelling should increase, whereas inhibition at the basolateral membrane should inhibit the rat cell swelling. Since bath phloretin inhibited cell swelling (Fig. 4), phloretin must inhibit basolateral urea transport. If the action of phloretin is limited to the basolateral membrane, we calculate that phloretin inhibited the basolateral membrane $P_{\text {urea }}$ by $85 \%$ (unpublished modeling results). This calculation assumes a relative basolateral:apical membrane $P_{\text {urea }}$ of 2 in the absence of phloretin (see below).

Basolateral membrane $\sigma_{\text {urea }}$. In the series of experiments presented above, we assumed that urea enters the cell only by diffusion $\left(\sigma_{\text {urea }}=1\right)$, and not by solvent drag $\left(\sigma_{\text {urea }}<1\right)$. While this is true for the phloretin-sensitive component of the urea flux (since phloretin inhibited urea but not water transport), the phloretin-insensitive component of urea flux could be coupled to water. If so, we would overestimate the $P_{\text {urea }}$ because $(a)$ urea would enter the cell by solvent drag in addition to diffusion; and $(b)$ some of the initial water flux into the cell would be driven by the difference in effective osmotic pressure of the two compartments independent of urea movement into the cell. Therefore, five tubules were perfused with a fluorinated hydrocarbon and bathed with solution A containing $0.25 \mathrm{mM}$ phloretin. Addition of mannitol (100 mosmol $/ \mathrm{kg}$ $\mathrm{H}_{2} \mathrm{O}$ ) decreased cell height with a time constant of $672 \pm 48 \mathrm{~ms}$, corresponding to a basolateral $P_{\mathrm{f}}$ of $50 \pm 4.5 \mu \mathrm{m} / \mathrm{s}$. Isosmotic addition of urea (100 mosmol/ $\mathrm{kg} \mathrm{H}_{2} \mathrm{O}$ urea replacing manni-

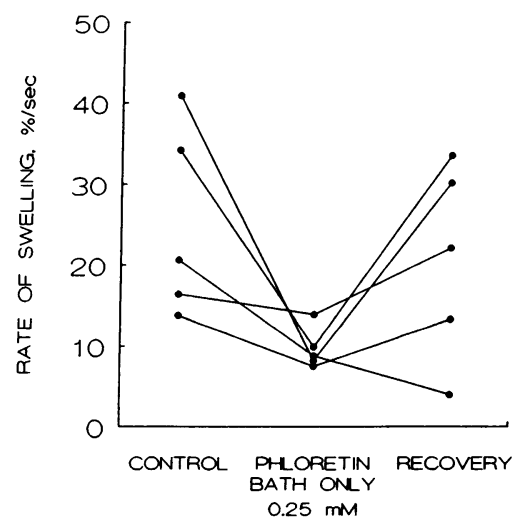

Figure 4. Effect of 0.25 $\mathrm{mM}$ phloretin on rate of cell swelling of IMCD cell induced by rapid replacement of urea $(100 \mathrm{mosmol} / \mathrm{kg}$ $\mathrm{H}_{2} \mathrm{O}$ ) for mannitol without change in bath osmolality (380 mos$\mathrm{mol} / \mathrm{kg} \mathrm{H} \mathrm{H}_{2} \mathrm{O}$ ). tol) caused an increase in cell height at a rate of $10.0 \pm 5.0$ percent $/ \mathrm{s}$, which corresponds to a basolateral membrane $P_{\text {urea }}$ of $2.0 \pm 0.5 \times 10^{-5} \mathrm{~cm} / \mathrm{s}$, assuming $\sigma_{\text {urea }}=1$. The basolateral solution was returned to solution A for 30-60 s, allowing urea to leave the cell. Urea $\left(100 \mathrm{mosmol} / \mathrm{kg} \mathrm{H}_{2} \mathrm{O}\right)$ was again added to the basolateral solution, but now associated with an increase in basolateral osmolality. We saw a transient decrease in cell height (osmotic abstraction due to the increased osmolality of the bath) followed by an increase in cell height back toward the initial cell height (urea entry into the cell) (Fig. 5). Analysis by the mathematical model ${ }^{3}$ (see Appendix) using a two-dimensional parameter search revealed a urea permeability of $2.1 \pm 0.4 \times 10^{-5} \mathrm{~cm} / \mathrm{s}$ and a $\sigma_{\text {urea }}$ of $1.00 \pm 0.05$. There was no significant difference between the urea permeability measured directly (calculated assuming $\sigma_{\text {urea }}=1$ ), and the urea permeability determined by the two-dimensional parameter search.

Relative basolateral to apical $P_{\text {urea }}$. The relative basolateral and apical $P_{\text {urea }}$ was assessed by measuring the initial rate of cell height increase following isosmotic addition of urea to either the bath or lumen. Tubules were dissected, perfused, and bathed with solution A containing mannitol (100 mos$\mathrm{mol} / \mathrm{kg} \mathrm{H}_{2} \mathrm{O}$ ). Fig. 6 shows a tracing from a typical study. In five tubules, isosmotic addition of urea (urea replacing mannitol) to the bath increased cell height at an average rate of $25.2 \pm 1.9$ percent/s with a steady-state increase in cell height of $33.2 \pm 2 \%$. In contrast, a similar isosmotic addition of urea to the luminal perfusate caused a small but significant increase in cell height at a rate of $3.0 \pm 1.0$ percent/s with a steady-state increase in cell height of $5.5 \pm 1.8 \%$. Subsequent isosmotic addition of urea to the bath increased cell height at a rate not significantly different from the control period. The rate of change and the extent of increase in cell height caused by isosmotic addition of urea to the bath was significantly greater than that caused by isosmotic addition of urea to the lumen, indicating that the basolateral membrane is more permeable to urea than the apical membrane (see Discussion).

\section{Discussion}

These studies examine the pathway for urea movement across the rat IMCD by measuring the apical and basolateral membrane urea permeabilities of the IMCD cell. While membrane water permeability has been studied in a variety of vesicles,

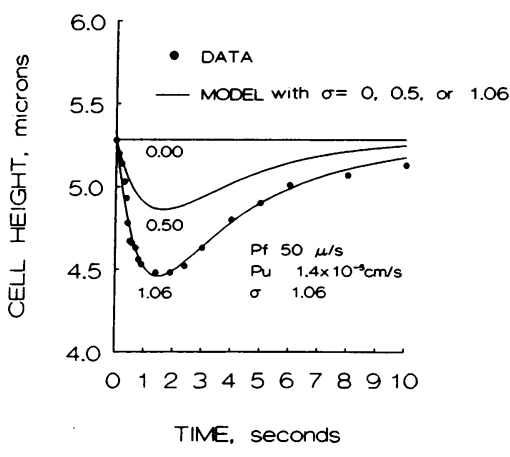

Figure 5. Typical experiment showing effect on cell height of IMCD cell induced by rapid addition of urea $(100$ mos$\mathrm{mol} / \mathrm{kg} \mathrm{H}_{2} \mathrm{O}$ ) in presence of $0.25 \mathrm{mM}$ phloretin (filled circles). Bath osmolality increased by $100 \mathrm{mosmol} / \mathrm{kg} \mathrm{H}_{2} \mathrm{O}$. Experimental data was used to estimate $P_{\text {urea }}$ and $\sigma_{\text {urea }}$ (see text). Solid curves predicted for $\sigma_{\text {urea }}$ of $0,0.5$, and 1.06 using shown $P_{\mathrm{f}}$ and $\mathrm{P}_{\text {urea }}$ by mathematical model of IMCD cell. $P_{\mathrm{f}}$ determined in same cell during a previous period (not shown). 


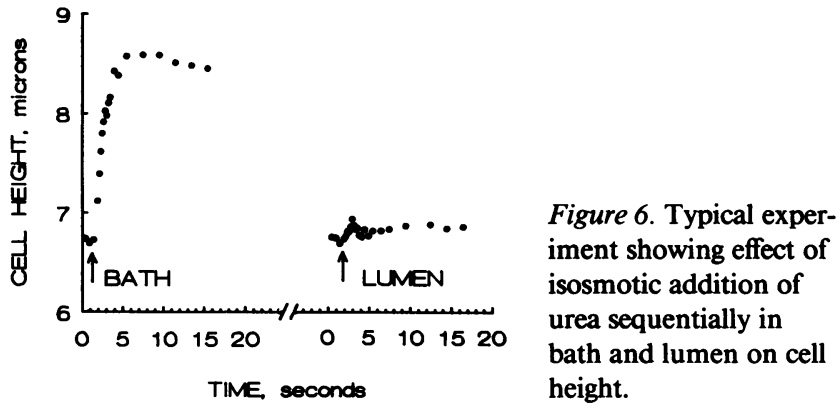

endosomes, cells, and epithelia $(18,26)$, this is the first quantitative determination of membrane urea permeability in a polarized epithelium. We will first discuss several methodological concerns, then discuss the physiological implications of the results.

Methodology. The equipment and experimental design employed is similar to that used for measurement of membrane water permeability in renal tubules (18), and hence fulfills the criteria for accurate measurement of membrane water permeability (18): (a) rapid step change in extracellular composition; $(b)$ absence of significant external unstirred layers; and $(c)$ accurate measurement of peak volume flow across the membrane. Since urea entry into the cell rapidly dissipates the transmembrane osmotic gradient, transmembrane water flow was slower following isosmotic addition of urea $\left(t_{1 / 2} 655 \pm 75\right)$ than after raffinose addition $\left(t_{1 / 2} 509 \pm 57 \mathrm{~ms}\right)$. Therefore, the methodology is also fast enough to measure $P_{\text {urea }}$ accurately.

Measurement of membrane urea permeability from changes in cell volume is complicated by the possibility of solvent drag, i.e., convective transport of urea through water channels. If so, the urea reflection coefficient $\left(\sigma_{\text {urea }}\right)$, which measures the interaction between urea and water transport, will be $<1$. The $\sigma_{\text {urea }}$ can be measured using several protocols (null method, analysis of initial water flow, or analysis of volume versus time curve) (27). In the null method, the reflection coefficient is calculated from the concentration of solute outside the cell needed to prevent the volume flow induced by a known concentration of impermeant solute inside the cell. The null method is precluded because urea entry into the cell induces a volume flow at any nonzero urea concentration, even in the presence of phloretin (Fig. 5). In the second method, the reflection coefficient is calculated from the ratio of initial volume flows induced by osmotic gradients of a test solute (i.e., urea) and an impermeant solute (i.e., raffinose). Ignoring urea movement leads to underestimation of $\sigma_{\text {urea }}$ because the high membrane urea permeability dissipates the transmembrane urea gradient as a result of urea entry into the cell (11). Because the first two methods are not applicable for use with a permeant solute, we determined the basolateral membrane $\sigma_{\text {urea }}$ using analysis of the detailed volume versus time curve. While theoretical problems exist (27), this method has been validated in membrane vesicles against the other two methods (27).

Basolateral membrane water permeability. After blocking transport across the apical membrane, increase in bath osmolality by $100 \mathrm{mosmol} / \mathrm{kg}$ caused the cells to shrink by $86 \%$ of that predicted for a perfect osmometer. This nonideal response could be caused by intrinsic volume regulation; however, IMCD cells exhibit intrinsic volume regulation following ex- posure to hyperosmotic solutions ( $390 \mathrm{mosmol} / \mathrm{kg} \mathrm{H}_{2} \mathrm{O}$ ) only in the presence of vasopressin (23). Because the present studies were preformed in the absence of vasopressin, the nonideal behavior is more likely caused by an osmotically inactive volume, as found by others $(18,23,25,28)$. The measured basolateral water permeability was $69.1 \pm 12.8 \mu \mathrm{m} / \mathrm{s}$, which is similar to that recently reported by others in the terminal IMCD (25) and rabbit CCD (18), but less than that of the rabbit proximal tubule and erythrocyte membrane (reviewed in $(14,26))$.

Basolateral membrane contains a specialized urea transporter. Because transport of urea across the cell might confound interpretation of the results, transport across the apical membrane was blocked in the initial studies. Isosmotic addition of urea to the basolateral solution rapidly increased cell height (Fig. 2); the rate of cell height increase was inhibited $55 \%$ by bath phloretin (Fig. 4) which blocks the erythrocyte urea pathway $(13,14)$. This indicates that the cell swelling after isosmotic addition of urea was caused by rapid influx of urea, in part, via a phloretin-sensitive pathway. It is conceivable that urea could enter the cells via a water channel. That phloretin inhibited basolateral urea transport without affecting the basolateral water permeability (Fig. 3) indicates that water and urea transport are largely independent. However, phloretin did not completely block urea entry into the cell, raising the possibility that the phloretin-insensitive portion is via water channels. This too can be excluded since the basolateral membrane $\sigma_{\text {urea }}$ was not significantly different from 1 in the presence of phloretin, indicating that urea and water transport are also independent in the presence of phloretin. Since we could find no evidence for coupling of urea and water either in the absence or presence of phloretin, we conclude that urea crosses the basolateral membrane predominantly by diffusion.

In the absence of vasopressin, the basolateral $P_{\text {urea }}$ is $14.2 \pm 4.2 \times 10^{-5} \mathrm{~cm} / \mathrm{s}$, which is similar to that of the erythrocyte but much greater than that of an artificial lipid bilayer or the lipid portion of the erythrocyte membrane (14). Inhibition by phloretin and the lack of solvent drag confirm the previous suggestion that basal urea transport is facilitated by a specialized urea transporter (4) present on the basolateral membrane of the IMCD cell.

Recent studies have found that the transepithelial $\sigma_{\text {urea }}$ is also $1(11,12)$. Because both the basolateral and transepithelial $\sigma_{\text {urea }}$ is 1 , urea moves across both cell membranes by diffusion and not by solvent drag, suggesting that urea and water pathways are distinct and independent $(11,12)$, as in rabbit brush border membrane vesicles (26) and erythrocytes (14). Previous reports of transepithelial $\sigma_{\text {urea }}<1,(10,29)$ may have underestimated $\sigma_{\text {urea }}$ because of dissipation of transepithelial urea gradients by passive diffusion of urea (11).

Apical membrane limits transcellular urea permeation. Transcellular movement of urea is suggested by the disparity in steady-state increase in cell height between the first and second period of Fig. 6 . If urea only crossed one membrane, then the steady-state volume should have increased by $35.7 \%$ in both periods. However, this clearly did not occur following isosmotic addition of urea to the lumen. Since it is unlikely that the cell would act as an ideal osmometer in one direction but not in the other, the results are more consistent with urea entering the cell across the apical membrane and then leaving the cell via the basolateral membrane. Therefore, the apical 
membrane is the barrier to transcellular urea diffusion, as found in the toad urinary bladder $(30,31)$.

The relative urea permeabilities were estimated from the initial changes in cell height following isosmotic addition of urea to the apical and basolateral solutions taking into account that urea can cross both membranes. Using water permeability measured previously and assuming that urea moves only by diffusion and not by solvent drag, the surface area-corrected $P_{\text {urea }}$ of the basolateral membrane is $\sim 2$.1-fold higher than that of the apical membrane. The absolute apical and basolateral membrane $P_{\text {urea }}$ is strongly dependent on the choice of water permeability, which was not measured in these cells. However, the relative apical and basolateral membrane $P_{\text {urea }}$ is 2.1 over a range of $P_{\mathrm{f}}$ tested (70-125 $\left.\mu \mathrm{m} / \mathrm{s}\right)$. The $P_{\text {urea }}$ of the apical membrane is also much larger than simple lipid permeability, confirming that urea also crosses the apical membrane through a specialized pathway. The data suggest that the apical and basolateral membranes have different urea permeabilities. Whether the apical and basolateral membranes have different urea transporters or different numbers of the same urea transporters is unknown.

Urea crosses the epithelium by a transcellular route. We estimated the transcellular urea permeability from the measured basolateral membrane $P_{\text {urea }}$, the relative apical to basolateral membrane $P_{\text {urea }}$, and the relative membrane surface areas by treating the cell as two parallel membranes. The minimum basolateral membrane urea permeability was used in this calculation. In the absence of vasopressin, the calculated transcellular urea permeability is $22.4 \times 10^{-5} \mathrm{~cm} / \mathrm{s}$, which is close to the transepithelial urea permeability of $17-25 \times 10^{-5}$ $(4,20)$. Thus, the permeability of the transcellular route is large enough to account for the transepithelial urea permeability, implying that the major pathway for transepithelial urea diffusion is through the cell, as suggested previously based on the high urea to creatinine or raffinose permeability (4).

Physiological significance. Accumulation of urea in the inner medullary interstitium occurs by passive diffusion of urea from the terminal $\operatorname{IMCD}(3,4)$. The measured apical and basolateral membrane urea permeabilities are sufficiently large so that urea transport across the terminal IMCD occurs by a transcellular route. Since transcellular urea permeation is limited by the apical membrane, it is likely that vasopressin increases the transepithelial urea permeability by modulating the urea permeability of the apical membrane, as occurs for water transport in the cortical collecting duct and toad urinary bladder. Based on evidence that vasopressin does not change the affinity of the transepithelial pathway for the urea analogue thiourea, it seems likely that vasopressin increases the number of transporters rather than alters the affinity for urea (8). Vasopressin causes an initial rapid rise in urea permeability over the first $5 \mathrm{~min}$, then a slow secondary rise to a maximal value at $40 \mathrm{~min}(20)$. This complex biphasic temporal stimulation suggests that regulation may occur at several sites, perhaps including the basolateral membrane, as proposed for vasopressin-stimulated water permeability $(32,33)$.

The high urea permeability of the basolateral membrane may allow the cell to respond rapidly to changes in interstitial urea concentration without large changes in cell volume, as might occur during changes from antidiuresis to water diuresis. Whether this transporter is present in other segments which traverse the inner medulla would be of interest.

\section{Appendix}

The model consists of three differential equations describing mass balances for urea, other non-urea solutes, and the volume of the cell as a function of time. For the purpose of the model, all NUS were lumped together as a single solute. The first equation describes the osmotic transport of water into the cell across the apical and basolateral membrane:

$\frac{\mathrm{d}}{\mathrm{d} t} V=S A_{\text {apical }} J_{\mathrm{v}, \text { apical }}+S A_{\mathrm{bl}} J_{\mathrm{v}, \mathrm{bl}}$

where $V$ is the volume of the cell, and $S A_{\mathrm{j}}$ and $J_{\mathrm{v}, \mathrm{j}}$ are the surface area and transmembrane water flow for membrane j. Solute or volume flow greater than zero indicates entry into the cell.

The other two conservation equations describe the transmembrane flow of urea $(i=1)$ and NUS $(i=2)$ :

$\frac{\mathrm{d}}{\mathrm{d} t}\left(V C_{\mathrm{i}, \text { cell }}\right)=S A_{\text {apical }} J_{\mathrm{i}, \text { apical }}+S A_{\mathrm{bl}} J_{\mathrm{i}, \mathrm{bl}}$

where $C_{i, j}$ is the concentration of solute $i$ in compartment $\mathrm{j}$, and $J_{\mathrm{i}, \mathrm{j}}$ is the transmembrane flux of solute $i$ across membrane $j$.

Standard equations taken from nonequilibrium thermodynamics are used to describe the transmembrane transport of solute and solvent. The equations describing transport across the $\mathrm{j}^{\text {th }}$ membrane are:

$J_{\mathrm{v}, \mathrm{j}}=P_{\mathrm{f}, \mathrm{j}} V_{\mathrm{w}} \sum_{\mathrm{i}=1}^{2}\left[\sigma_{\mathrm{i}, \mathrm{j}} \gamma_{\mathrm{i}}\left(C_{\mathrm{i}, \mathrm{cell}}-C_{\mathrm{i}, \mathrm{j}}\right)\right]$

$J_{\mathrm{i}, \mathrm{j}}=P_{\mathrm{i}, \mathrm{j}}\left(C_{\mathrm{i}, \mathrm{j}}-C_{\mathrm{i}, \text { eell }}\right)+\left(1-\sigma_{\mathrm{i}, \mathrm{j}}\right) J_{\mathrm{v}} C_{\mathrm{i}, *}$

where $P_{\mathrm{f}, \mathrm{j}}$ and $P_{\mathrm{i}, \mathrm{j}}$ are the membrane permeabilities to water and the $\mathrm{i}^{\text {th }}$ solute; $V_{\mathrm{w}}$ is the molal volume of water $(18 \mathrm{ml} / \mathrm{mole}) ; \sigma_{\mathrm{i}, \mathrm{j}}$ is the reflection coefficient of the $\mathrm{i}^{\text {th }}$ solute across membrane $\mathrm{j} ; \gamma_{\mathrm{i}}$ is the osmotic coefficient of solute $\mathrm{i}$; and $C_{\mathrm{i}, *}$ is the concentration of solute $\mathrm{i}$ in the compartment of origin of the fluid flux [ $C_{\text {urea, cell }}$ for $J_{\mathrm{v}}<0$; $C_{\text {urea, bath }}$ for $\left.J_{\mathrm{v}}<0\right](11)$.

The system of differential equations with initial conditions describing the initial cell volume, cell and bath urea, and NUS concentrations was solved numerically using Gear's stiff method (DIVPAG subroutine, IMSL) on a personal computer. In all simulations, we assume that the membranes are impermeable to NUS, and that $\sigma_{\mathrm{NUS}}$ $=1$. The values for $\gamma$ were 1 for NUS and 0.96 for urea (11).

\section{Acknowledgments}

The author thanks Dr. Kenneth Spring and Dr. Scott Brady for help with the optical microscopy, and Rebecca Aricheta and Ebby Shawky for technical assistance.

This study was supported by National Institutes of Health grant DK-01888-01.

\section{References}

1. Berliner, R. W., N. G. Levinsky, D. G. Davidson, and M. Eden. 1958. Dilution and concentration of the urine and the action of antidiuretic hormone. Am. J. Med. 24:730-744.

2. Sands, J. M., and M. A. Knepper. 1987. Urea permeability of mammalian inner medullary collecting duct system and papillary surface epithelium. J. Clin. Invest. 79:138-147.

3. Knepper, M. A., and F. Roch-Ramel. 1987. Pathways of urea transport in the mammalian kidney. Kidney Int. 31:629-633.

4. Sands, J. M., H. Nonoguchi, and M. A. Knepper. 1987. Vasopressin effects on urea and $\mathrm{H}_{2} \mathrm{O}$ transport in inner medullary collecting duct subsegments. Am. J. Physiol. 253:F823-F832.

5. Madsen, K. M., W. L. Clapp, and J. W. Verlander. 1988. Structure and function of the inner medullary collecting duct. Kidney Int. 34:441-454.

6. Clapp, W. L., K. M. Madsen, J. W. Verlander, and C. C. Tisher. 
1989. Morphologic heterogeneity along the rat inner medullary collecting duct. Lab. Invest. 60:219-230.

7. Star, R. A. 1990. Basolateral membrane sodium-independent $\mathrm{Cl}^{-} / \mathrm{HCO}_{3}^{-}$exchanger in rat inner medullary collecting duct cell. $J$. Clin. Invest. 85:1959-1966.

8. Chou, C.-L., and M. A. Knepper. 1989. Inhibition of urea transport in inner medullary collecting duct by phloretin and urea analogues. Am. J. Physiol. 257:F359-F365.

9. Kondo, Y., and M. Imai. 1987. Effects of glutaraldehyde fixation on renal tubular function. I. Preservation of vasopressin-stimulated water and urea pathways in rat papillary collecting duct. Pflugers Arch. Eur. J. Physiol. 408:479-483.

10. Imai, M., J. Taniguchi, and K. Yoshitomi. 1988. Osmotic work across inner medullary collecting duct accomplished by difference in reflection coefficients for urea and $\mathrm{NaCl}$. Pfluegers Arch. Eur. J. Physiol. 412:557-567.

11. Knepper, M. A., J. M. Sands, and C.-L. Chou. 1989. Independence of urea and water transport in rat inner medullary collecting duct. Am. J. Physiol. 25:F610-F621.

12. Chou, C.-L., J. M. Sands, H. Nonoguchi, and M. A. Knepper. 1990. Urea gradient-associated fluid absorption with $\sigma_{\text {urea }}=1$ in rat terminal collecting duct. Am. J. Physiol. 258:1173-1180.

13. Macey, R. I., and R. E. L. Farmer. 1970. Inhibition of water and solute permeability in human red cells. Biochim. Biophys. Acta. 211:104-106

14. Macey, R. I. 1984. Transport of water and urea in red blood cells. Am. J. Physiol. 246:C195-C203.

15. Yousef, L. W., and R. I. Macey. 1989. A method to distinguish between pore and carrier kinetics applied to urea transport across the erythrocyte membrane. Biochim. Biophys. Acta. 984:281-288.

16. Morgan, T., and R. W. Berliner. 1968. Permeability of the loop of Henle, vasa recta, and collecting duct to water, urea, and sodium. Am. J. Physiol. 215:108-115.

17. Sands, J. M., H. Nonoguchi, and M. A. Knepper. 1988. Regulation of urea and water transport by vasopressin in renal inner medullary collecting ducts. In Vasopressin: Cellular and Integrative Functions. A. W. Cowley, Jr., J.-F. Liard, and D. A. Ausiello, editors. Raven Press, Ltd., New York. 137-142.

18. Strange, K., and K. R. Spring. 1987. Cell membrane water permeability of rabbit cortical collecting duct. J. Membr. Biol. 96:2743.

19. Reuss, L., and C. U. Cotton. 1989. Water transport across ADH-sensitive epithelia. In Contemporary Nephrology. S. Klahr, and S. G. Massry, editors. Plenum Publishing Corp., New York. 1-33.
20. Star, R. A., H. Nonoguchi, R. Balaban, and M. A. Knepper. 1988. Calcium and cyclic adenosine monophosphate as second messengers for vasopressin in the rat inner medullary collecting duct. $J$. Clin. Invest. 81:1879-1888.

21. Burg, M. B. 1972. Perfusion of isolated renal tubules. Yale J. Biol. Med. 45:321-326.

22. Strange, K., and K. R. Spring. 1986. Methods for imaging renal tubule cells. Kidney Int. 30:192-200.

23. Sun, A., and S. C. Hebert. 1989. Rapid hypertonic cell volume regulation in the perfused inner medullary collecting duct. Kidney Int. 36:831-842.

24. Marsh, D. J., P. K. Jensen, and K. R. Spring. 1984. Computerbased determination of size and shape in living cells. J. Microsc. (Oxf.). 137:281-292.

25. Flamion, B., and K. R. Spring. 1990. Water permeability of the basolateral membrane of rat inner medullary collecting duct cells. Am. J. Physiol. In press.

26. Verkman, A. S. 1989. Mechanisms and regulation of water permeability in renal epithelia. Am. J. Physiol. 257:C837-C850.

27. Chen, P. Y., D. Pearce, and A. S. Verkman. 1988. Membrane water and solute permeability determined quantitatively by selfquenching of an entrapped fluorophore. Biochemistry. 27:5713-5718.

28. Guggino, W. B., H. Oberleithner, and G. Giebisch. 1985. Relationship between cell volume and ion transport in the early distal tubule of the Amphiuma kidney. J. Gen. Physiol. 86:31-58.

29. Rocha, A. S., and J. P. Kokko. 1974. Permeability of medullary nephron segments to urea and water: effect of vasopressin. Kidney Int. 6:379-387.

30. Maffly, R. H., R. M. Hays, E. Lamdin, and A. Leaf. 1960. The effect of neurohypophyseal hormones on the permeability of the toad bladder to urea. J. Clin. Invest. 39:630-641.

31. Rapoport, J., J. W. Mills, N. Franki, and H. H. Church. 1985. Autoradiographic studies of solute transport across the toad bladder. Kidney Int. 27:726-730.

32. Kachadorian, W. A., S. Sariban-Sohraby, and K. R. Spring. 1985. Regulation of water permeability in toad urinary bladder at two barriers. Am. J. Physiol. 248:F260-F265.

33. W. Kachadorian, K. R. Spring, N. L. Shinowara, J. Muller, T. A. Palaia, and V. A. DiScala. 1990. Effects of serosal hypertonicity on water permeability in toad urinary bladder. Am. J. Physiol. 258:C871-C878.

34. Verkman, A. S. 1980. The quenching of an intramembrane fluorescent probe: a method to study the binding and permeation of phloretin through bilayers. Biochim. Biophys. Acta. 599:370-379. 